\title{
A Systematic Review of Household and Family Alcohol Use and Childhood Neurodevelopmental Outcomes in Low- and Middle-Income Countries
}

\author{
Tausif Huq ${ }^{1}$ - Emma C. Alexander ${ }^{2,3} \cdot$ Logan Manikam $^{3,4} \oplus$ - Tahir Jokinen ${ }^{1} \cdot$ Priyanka Patil $^{3,4}$. Darrin Benjumea ${ }^{5}$. \\ Ishani Das ${ }^{5} \cdot$ Leslie L. Davidson $^{5}$
}

Accepted: 9 December 2020 / Published online: 28 December 2020

(c) The Author(s) 2020

\begin{abstract}
Childhood exposure to alcohol misuse by household adults has been related to childhood developmental delay, cognitive impacts, mental illness, and problem behaviours. Most evidence comes from high income countries. This systematic review only included studies from low- and middle-income countries (LMICs). Five databases were searched from 1990-2020. Twenty-eight studies of children 0-12 years were included, with 42,599 participants from 11 LMICs. The most common outcome was behavioural problems/disorders (19 studies). Despite varying study designs, this review found that alcohol misuse by household members in LMICs is associated with adverse child neurodevelopmental outcomes, although casual inferences cannot be drawn in the absence of well conducted prospective studies. Statistically significant correlations were described between parental alcohol misuse and child emotional and behavioural difficulties, cognitive delay, and risky behaviours. In future, prospective cohort studies are recommended, with adjustment for confounders.
\end{abstract}

Keywords Alcohol · Alcohol abuse · Low- and-middle income countries $\cdot$ Neurodevelopment $\cdot$ Behaviour problems . Children

\section{Introduction}

Experiences in childhood have been shown to have a significant impact both on concurrent health and development in later life [1-4]. This might be through exposure to social and environmental factors directly leading to the development

Supplementary Information The online version contains supplementary material available at https://doi.org/10.1007/s1057 8-020-01112-3.

Logan Manikam

logan.manikam.10@ucl.ac.uk

GKT School of Medical Education, King's College London, London, UK

2 Paediatric Liver, GI and Nutrition Centre and Mowatlabs, King's College Hospital, London, UK

3 Aceso Global Health Consultants Limited, London, UK

4 UCL Institute of Epidemiology and Health Care, University College London, London WC1E 7HB, UK

5 Mailman School of Public Health, Columbia University, New York, USA of particular diseases, or more indirectly, with childhood experiences shaping attitudes and future health behaviours.

The growing evidence, predominantly from high-income countries, of the life-long impact of early adversity has led to the association of early adversity with adult disease outcomes such as poor self-rated health, diabetes, obesity, heart and lung disease, stroke, and cancer [5-7]. This association has even been extended to an increased risk of premature death $[8,9]$. One possible mechanism for this association is through adversity encouraging health-harming behaviours and reduced self-efficacy as adults [10]. There is also a notable association between early adversity and various risk behaviours and mental health problems [11, 12] including adult alcoholism [13], depression [14], and suicidality [15]. However, while many of these aforementioned consequences become apparent later in adulthood, in some cases the impact of negative experiences on children can be observed in early life $[16,17]$.

Household substance abuse has been frequently cited as one of a number of adverse childhood experiences (ACEs), alongside mental illness, conflict, neglect, or abuse, which have been particularly associated with harmful child 
neurodevelopmental and behavioural outcomes [18]. In particular, a growing number of studies, primarily from high income countries, have documented the negative consequences of childhood exposure to a household member who misuses alcohol. Harmful or problem drinking by parents, caregivers, or others in the household can disrupt family relationships, place children under chronic mental, physical and physiological stress, and lead to injury, abuse and neglect. Associated consequences in terms of child health and development potential include developmental delays, cognitive impacts, behaviour problems in younger children, and a range of problem behaviours in adolescence such as absence from school, substance abuse, and teenage pregnancy. Studies in high-income countries have reported adverse neurodevelopmental outcomes regarding children's cognitive and academic performance [19], adolescent alcohol and illicit drug use [3], and externalisation behaviour difficulties [20, 21]. Some studies suggest a dose-dependent relationship for adverse experiences whereby an accumulation of adverse exposures, including parental alcohol abuse, can lead to a higher risk of negative outcomes, including poorer health and mental health and later substance abuse by the child [1,22, 23].

Since household alcohol consumption patterns are dependent on societal and economic factors affected by the culture and the income status of a country, it is not necessarily appropriate to extrapolate evidence gathered from high income settings to children from low- and middle-income countries (LMICs). Family units tend to be more cohesive in LMICs than in high-income countries, with intergenerational coresidence [24] potentially increasing the number of caregivers in the home who could engage in alcohol misuse around a young person [25]. The presence of multiple caregivers could also be a protective factor. Thus far there has not been a systematic review of the impact of household alcohol misuse on children from LMICs. This paper aims to synthesise the results of studies from subjects living in lowand middle-income countries, in the hope that findings can inform directions for future research and potentially inform policy recommendations.

In particular, there is evidence to indicate that the impact of exposure on children under 13 years compared to adolescents may differ. Brain development undergoes rapid advancement in the early years; for example it quadruples in weight, and acquires $90 \%$ of adult volume, before the age of six [26]. Early childhood stressors lead to increased activation of the hypothalamic-pituitary-adrenal axis and glucocorticoid release, causing changes in glucocorticoidsensitive areas of the brain such as the hippocampus, amygdala and prefrontal cortex $[27,28]$. In a rat model, early exposure to stressed and abusive caretakers led to persistent changes in methylation of brain-derived neurotrophic factor DNA and subsequent gene expression in the prefrontal cortex [29]. In a study of MRI scans of children exposed to early life stress, these children had smaller hippocampal and amygdala volumes than controls [30]. In later childhood, grey matter volume relative to white matter peaks, and later decreases during adolescence [31]. Adolescent brain development occurs asymmetrically with the limbic system and reward system developing faster than the prefrontal cortex, believed to explain why adolescents may tend towards risktaking behaviour [32]. Furthermore, behavioural and neurodevelopmental changes in adolescence are affected by the onset of puberty and concurrent hormonal changes leading to changes in neuronal development and cognitive function $[33,34]$. The neurodevelopmental influence of exposures will therefore differ according to the age at which they are experienced, the number of times they have been experienced, and potentially the age at which a young person receives medical care. Therefore an independent examination of the evidence for the impact of household alcohol consumption on children, relative to adolescents, is useful. This particular review article focuses on childhood developmental outcomes, specifically children aged $0-12$-years-old, alongside a parallel review focusing on adolescent behavioural outcomes [35].

1. To systematically identify studies of the impact of excess alcohol consumption among household adults on child developmental health outcomes (neurodevelopmental, cognitive and behavioural) in low- and middle-income countries and to evaluate the quality of the research

2. To explore whether the nature of alcohol use and misuse differs by individual family members (father, mother or other family member) in its impact on child health outcomes (including neurodevelopment, cognitive and behavioural impact) in low- and middle-income countries

\section{Methods}

A protocol for this review was published on the PROSPERO register in June 2017, registration number CRD42017070209.

\section{Eligibility Criteria}

Studies were included in this review if they met the following criteria:

- Participants: children and young people aged 0-12 years

- Exposure: adult household member engaging in alcohol misuse

- Setting: low- and middle-income countries as defined by the World Bank [36] 
- Outcome: Outcome measure of adverse child behavioural and neurodevelopmental impacts (excludes outcomes directly related to alcohol exposure such as children's own drinking behaviour as a result of adult alcohol exposure or in utero alcohol exposure)

- Language: Studies published in English, or with translation available

- Year: Published from 1990 or later

An initial pilot search had revealed that a number of varying terms were in use in the literature to describe disorders related to alcohol consumption, including terms 'problem drinking', 'hazardous alcohol use' 'alcoholism', 'drunkenness', 'alcohol abuse', 'alcohol addiction' amongst others. Between studies, there were also inconsistencies in defining these terms. For example, some authors used these terms strictly under the remit of validated alcohol screening questionnaires, whereas others defined exposure to alcohol more loosely and casually. Therefore, 'alcohol misuse' i.e. harmful use (ICD-11 code F10.1), is used throughout this paper in order to be consistent with the World Health Organisation, International Classification of Mental Disorders, 11th Revision (ICD-11) [37]. Studies with participants aged 0-12 years old were considered eligible; studies which only included a small minority of participants within this range were excluded. Studies which focused on antenatal, rather than household, alcohol exposure, were excluded due to the confounding influence of intrauterine toxic exposure to alcohol. ACE studies which included parental alcohol as one of a cumulative list of adverse childhood experiences without detailing the individual effect of alcohol misuse were excluded.

\section{Information Sources}

Five electronic databases were searched from 1990 to April of 2020: Medline, EMBASE, OVID Global Health, Cochrane Library and PsychInfo. An original June 2017 search was updated in June 2018 and in April 2020.

\section{Search Strategy}

The search strategy was structured as follows: "alcohol use" AND "household" AND "young person" AND "neurodevelopmental outcome(s)" with associated synonyms. The full search strings used for MEDLINE are available in Supplementary File 1. In order to ensure that no potentially relevant studies would be missed, the search term included alcohol 'use' to be deliberately broad and inclusive.

The returned results were then secondarily sorted using the Cochrane LMIC filter to screen for studies set in low and middle income countries (LMICs) [38]. This filter has been extensively used in systematic reviews of similar nature
[39-42]. During targeted abstract and full text review, further screening made use of the up to date World Bank list of LMICs [36].

\section{Study Selection and Data Extraction}

After the studies were downloaded, and the Cochrane LMIC filter had been applied, each title and abstract was reviewed by one reviewer and uncertainties checked by a second against the inclusion criteria. Shortlisted full-text articles were subsequently checked by two separate reviewers. This led to the final list of studies to be included.

A standardised pre-piloted extraction form was developed, tested on 10 articles and revised iteratively as needed. Extracted information included:

(1) Study characteristics: setting, study design, method of data-analysis;

(2) Participants: study population, number of participants in each group, patient characteristics

(3) Child or adolescent health outcome (as reflected in primary outcome)

(4) Household adult alcohol exposure or definition (as reflected in secondary outcome)

(5) Household location, income, food insecurity, asset index and family factors and other factors (if available)

Each study type was classified e.g. cohort, cross-sectional study, according to a standard definition [43]. Each study was also classified as relevant to adolescents, children, or both.

\section{Results Synthesis}

Because of the heterogeneity of both exposures and outcomes, the evidence reviewed is presented as a narrative report with results broadly categorized by outcome within the following categories:

- Child behavioural problem/disorder

- Child cognitive delay/disorder

- Risky behaviour

- Other

\section{Quality Assurance}

The National Heart, Lung and Blood Institute (NHLBI) Quality Assessment Tool for Observational Cohort and Cross-Sectional Studies was utilised to assess the quality of the included studies, or the equivalent tool for Case-Control studies if applicable [44]. The former tool asks 14 questions with answers of 'Yes', 'No' or 'Other', such as 'Was the exposure(s) assessed more than once over time?' Two 
reviewers independently screened each study, with additional arbitration where required to reach an overall score. A maximum score of 14 (12 for Case-Control studies) was available for each paper, and a minimum score of 0 , with higher scores indicating a high-quality paper relevant to our objectives. The scores were then used to produce an overall rating of 'Good', 'Fair' or 'Poor' relevant to the review, with studies rated as 'Poor' to be excluded from inclusion in the main results section.

\section{Results}

In total, 28,707 titles and abstracts were downloaded from the chosen databases. After addition of further filtering (namely the Cochrane LMIC filter [38]), 4,437 results were screened by title and abstract. Following this, 602 papers were selected for full text review. The process of study selection is illustrated in Fig. 1.

\section{Study and Participant Characteristics}

In total, 59 studies were identified and relevant to individuals aged $0-18$ years. Of these, 28 studies were focused on children $0-12$ years old, and were included in this review. The adolescent studies are summarised elsewhere [35].

Of these 28 studies relevant to outcomes in children, 18 were cross-sectional, five were case-control and five cohort studies. The studies came from 11 different low- and middle-income countries, with the most frequently studied country being India ( 8 studies); see Table 1 . Across these studies, there were 42,599 children/participants, with the age range across the included studies varying from 1.5 years to 20 years but predominantly focusing from $0-12$ years (Table 2).

\section{Quality Appraisal}

The NHLBI quality scores of the included studies are listed in Table 2. All studies included in this review are rated as
Fig. 1 Study selection process (Color figure online)

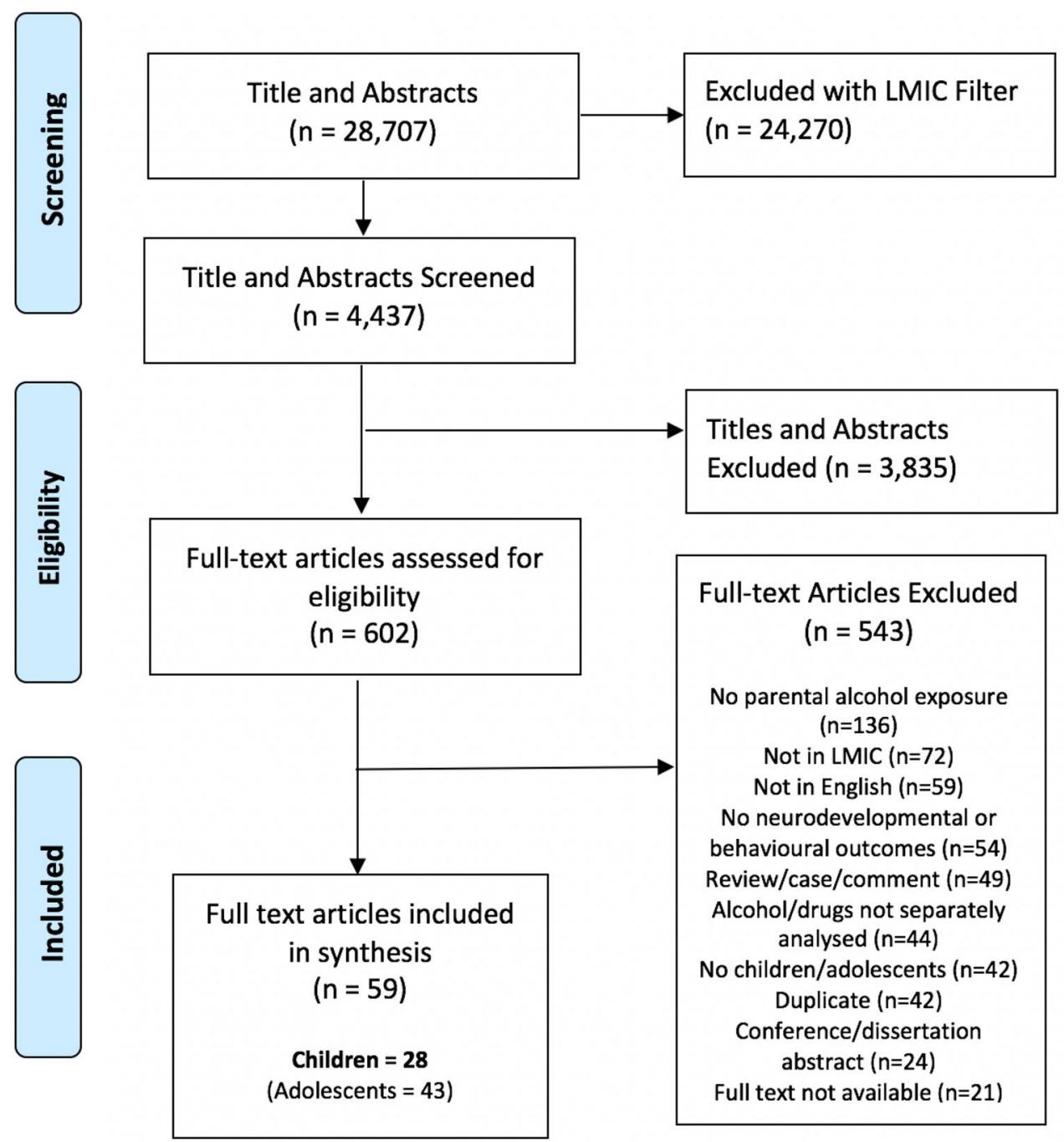


Table 1 Countries of origin of included studies

\begin{tabular}{ll}
\hline Country & Number of studies \\
\hline India & 8 studies $[45,47,50,51,56,59,71,76]$ \\
South Africa & 6 studies $[55,58,60,61,77,79]$ \\
Thailand & 3 studies $[49,54,62]$ \\
Turkey & 2 studies $[48,75]$ \\
Ukraine & 2 studies [46, 63] \\
Brazil & 2 studies [52, 72] \\
Russian Federation & 1 study [57] \\
Rwanda & 1 study [74] \\
Belarus & 1 study [53] \\
China & 1 study [73] \\
Malaysia & 1 study [78] \\
\hline
\end{tabular}

either Fair $(n=21)$ or Good $(n=7)$ (Table 2$)$. The most common reason for studies to score poorly was due to failure to measure continuous data for an independent variable (i.e. alcohol consumption), and for not defining alcohol consumption or misuse by any validated tool.

Most studies included in this review did not, or insufficiently, report information related to household income/ deprivation, assets index, food security, mental health and other related variables which may act as confounders or a mediating factor in childhood neurodevelopmental or behavioural outcomes when exposed to household alcohol misuse.

\section{Household Alcohol Exposure}

The exact nature of household alcohol exposure varied between studies. Across the 28 studies, 15 studies examined the impact of generic parental/caregiver/familial alcohol consumption on neurodevelopmental and behavioural outcomes in the child. Nine studies examined exposure to paternal alcohol consumption, and four studies looked at the effect of maternal alcohol consumption (Table 2).

\section{Neurodevelopmental and Behavioural Outcomes}

The most commonly investigated outcome was child behavioural problem or disorder, followed by child cognitive delay or disorder, and risk behaviour. The following sections examine the evidence for each of these outcomes in turn.

\section{Child Behavioural Problem or Disorder}

Neurodevelopmental aspects related to child behavioural problems/disorder was most frequently reported outcome. The outcome was measured in 19 of 28 included studies. Overall, 10 studies [45-54] described an overall significant correlation and/or association between alcohol exposure in household and a higher prevalence and/or severity of childhood behavioural problems/disorders. Six papers showed mixed results [55-60], whereas three papers [61-63] did not demonstrate any significant correlation and/or association.

A number of studies used validated questionnaires to assess childhood behavioural problems which included the Strengths and Difficulties Questionnaire [45, 53, 55, 58, 62], Childhood Behaviour Checklist (CBCL) [47, 56, 57, 60, 61], Childhood Psychopathology Measurement Schedule (CPMS) [50, 51, 59], the Rutter A2 Scale of Behaviour [52], and Youth Self-Report [63], whereas three studies [46, 48, 59] included development disorders, namely oppositional defiant disorder (ODD), Attention Deficit/Hyperactivity Disorder (ADHD) and Conduct Disorder (CD) as neurodevelopment outcomes (Supplementary Table S1).

Five studies explored child behaviour outcomes using the Strengths and Difficulties Questionnaire (SDQ) [45, 53, 55, 58, 62]. The SDQ is used to assess emotional and behavioural problems among children across a number of subscales and can be used to screen for and monitor psychological disorders $[64,65]$. It produces sub-scale scores for internalising and externalising behaviours, and the sum of these produces the total difficulties score. Overall, the five studies included 14,108 children with an age range of 3-11 years old, and showed an association between household member alcohol misuse and greater difficulties. Three studies [55, 58, 62] examined care-giver/parental alcohol misuse, and two examined father's use of alcohol $[45,53]$. Two cross-sectional studies in South Africa [55, 58] examining caregiver/parental alcohol exposure and showed an association with high total SDQ scores. In India, Bele et al. (2012) found having an alcoholic father was a significant predictor of scores showing an emotional or behavioural disorder [45]. In a Belarusian cross-section study of 11,305 children, authors found increased total difficulty SDQ scores in children whose fathers had heavy or moderate drinking habits (difference in score 0.9, 95\% Confidence Interval (CI) $0.5-1.4$ and $0.5,95 \%$ CI $0.1-0.8$ respectively) [53]. However, when stratifying scores, they found an association with increased scores for externalising behaviours (hyperactivity and conduct problems) but not for internalising behaviours (emotion and peer problems) after adjusting for confounders [53]. In contrast, in Thailand, Pajarn et al. (2012) did not demonstrate an association between parental alcohol misuse and SDQ scores [62].

The Child Behaviour Checklist (CBCL) is an instrument designed to assess behavioural and emotional disorders among children aged 4-16 years, with good reliability and validity in a variety of cultural and language settings [66-69]. It has eight domains, namely: emotionally reactive, anxious/depressed, somatic symptoms, withdrawn behaviour, sleep problems, common/non-specific problems, attention problems and aggressive behaviour. The first four 


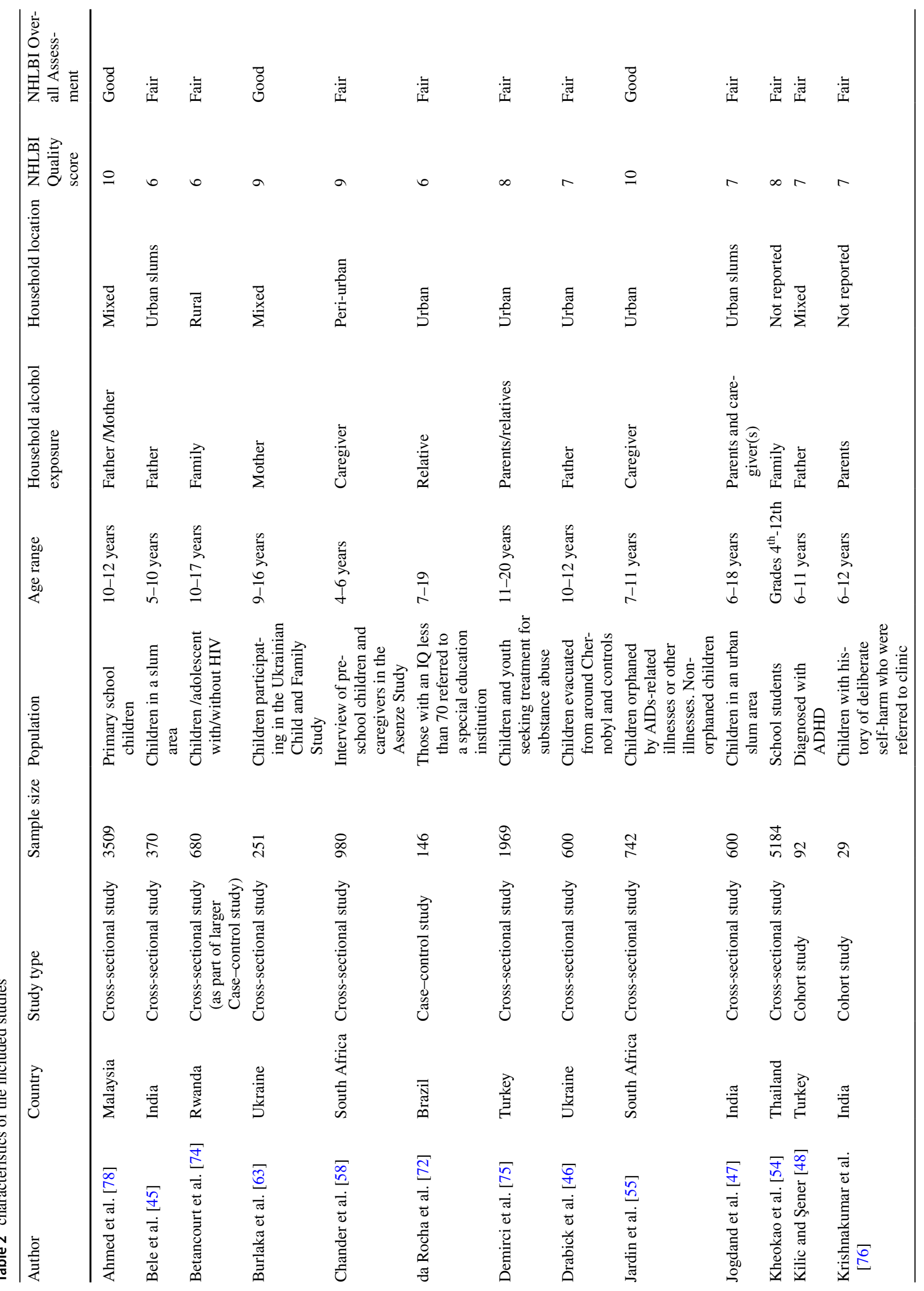




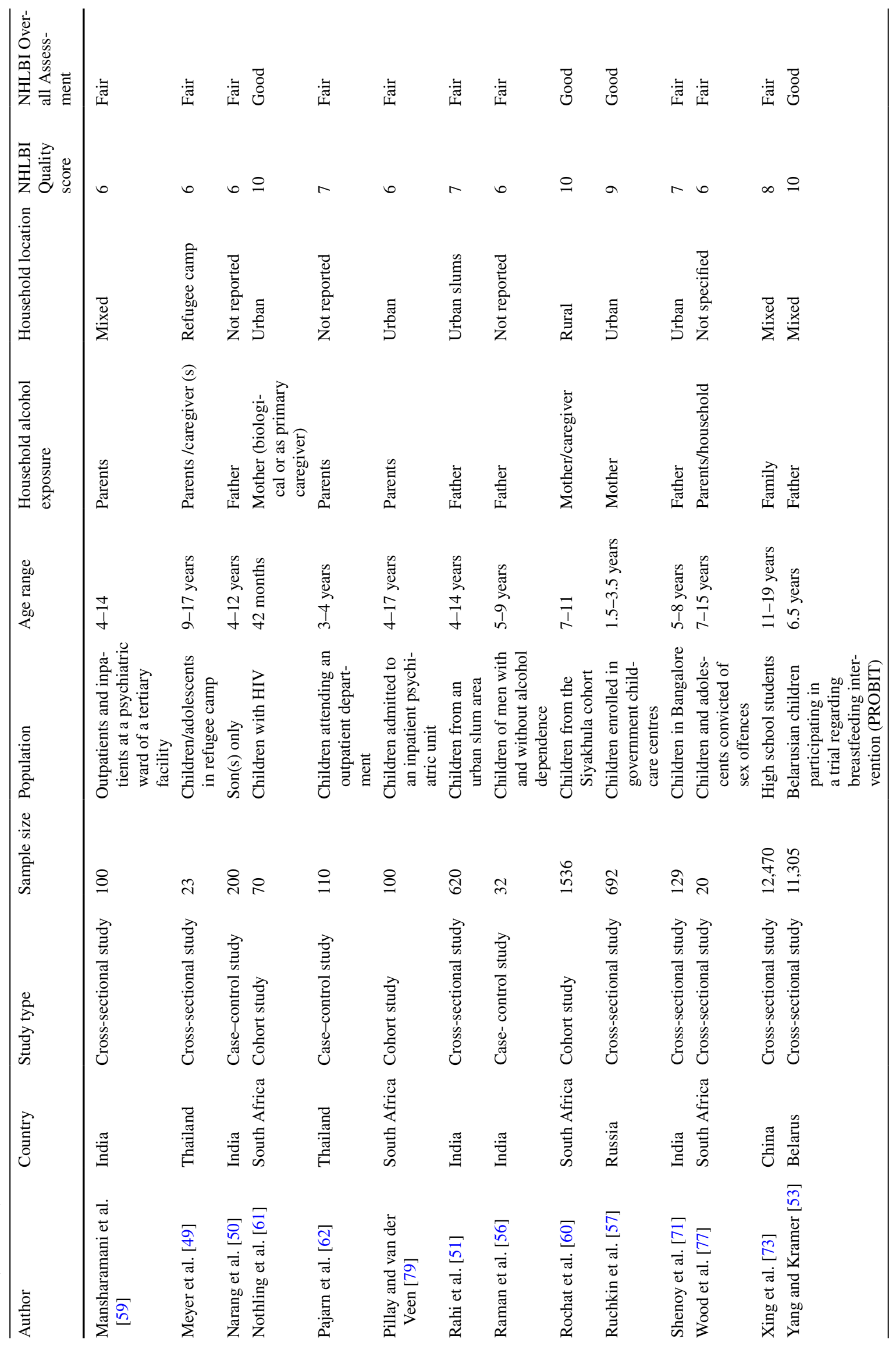


domains are categorised as internalising behaviour problems and the latter two as externalising behaviour problems. Five studies [47, 56, 57, 60, 61], reported child behavioural outcomes using CBCL with one study demonstrating a clear association [47]. These studies included children from South Africa ( $n=3)$, India, and Russia (Table 3). Jogdand et al. (2014) in India showed a clear association between alcoholism in the parent and overall higher odds of behavioural problems (Odds Ratio (OR) 1.56 (CI 1.12-2.17) p <0.05) [47]. In another Indian study, Raman et al. (2010) showed higher scores in externalisation behaviour $(\mathrm{p}<0.01)$, but no significant difference in internalising behaviour [56]. In South Africa, Rochat et al. (2019), children of mothers with hazardous drinking had higher mean scores for psychological problems (mean 45.0 if no hazardous drinking, 48.9 for hazardous drinking, $p=0.029$ ) [60]. They also found a significant association in univariate logistic regression between any alcohol use by mothers and children meeting referral thresholds for internalising/externalising problems, but this was no longer significant in multivariate analyses. In a second South African study, Nothling et al. (2013), found that maternal alcohol abuse did not have significant explanatory power for child behaviour problems in various models [61]. Ruchkin et al. (2008) in Russian children found children's aggressive and destructive behaviour to be significantly and positively (albeit weakly) correlated with alcohol amount, but not with alcohol frequency [57]. In an Ukrainian study, Burlaka et al. (2017) used the Youth Self-Report questionnaire (which is a parallel form to the CBCL) specifically looking at maternal alcohol use, and found no statistically significant correlation with child internalisation problems [63].

Three studies used the Childhood Psychopathology Measurement Schedule (CPMS) to measure behavioural outcomes in Indian children exposed to household paternal alcohol use $[50,51,59]$. CPMS was originally developed in India by Malhotra et al. (1988), which is an adaptation of the CBCL for Indian children [70]. Narang et al. (1997) and Rahi et al. (2005) found significantly higher score in negative behaviours and lower scores in positive behaviours in those exposed to household paternal alcohol consumption (Table 3) [50, 51]. Mansharamani et al. (2018) described significantly higher mean total CPMS scores in children of alcoholics compared to non-alcoholics [59]. Adjustment for potential confounding factors did not take place in these studies.

In Brazil, Zanoti-Jeronymo et al.[52] used the Rutter A2 Scale of Behaviour in Children and found an overall higher score in emotional and behavioural problem aspects in children of alcoholic parents compared to non-alcoholic parents (Median 16.5 vs $8, \mathrm{p}=0.00016)$. In the only qualitative study included in this systematic review, Meyer et al. (2013) examined the effect of chronic stressors on refugee children 


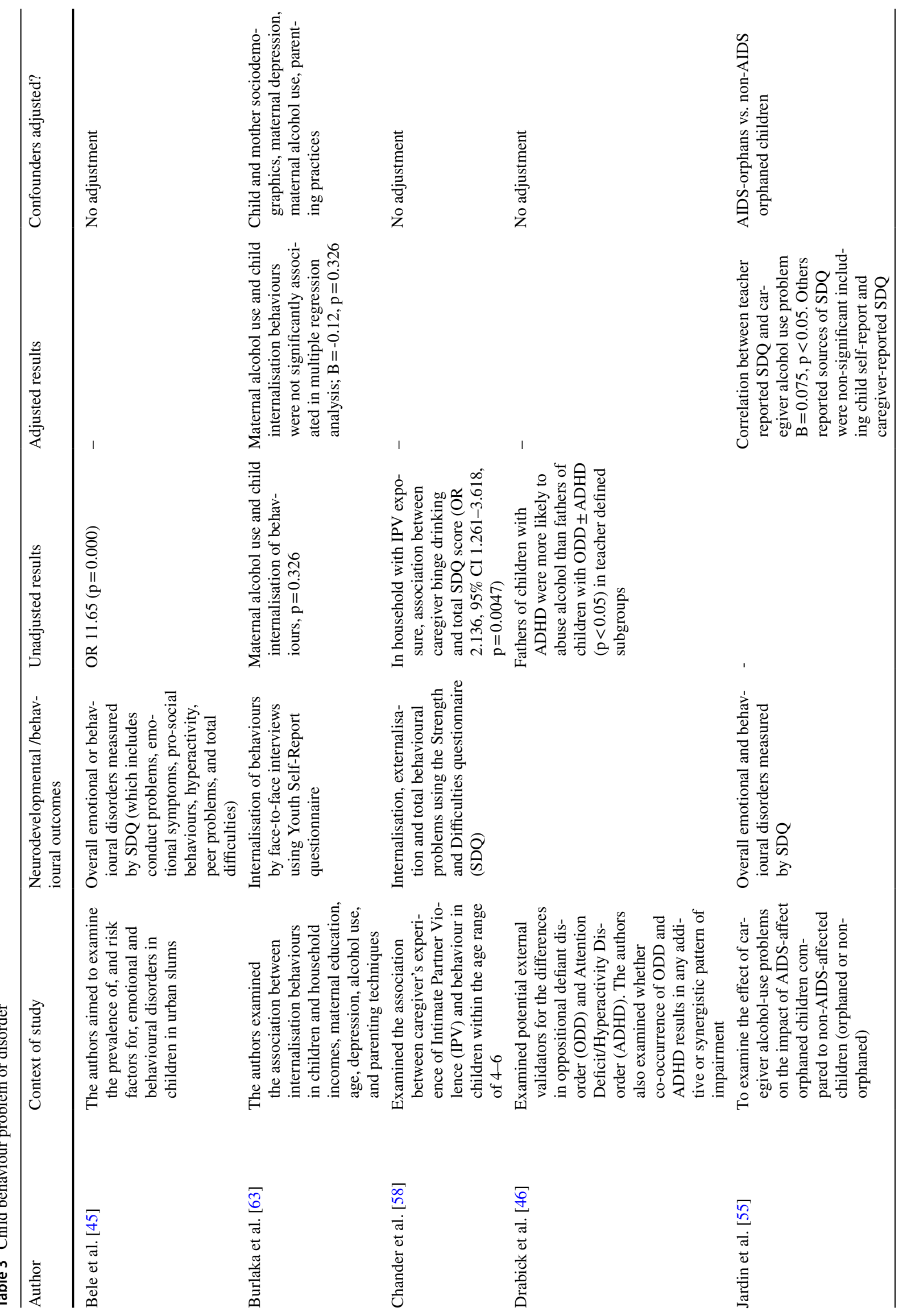




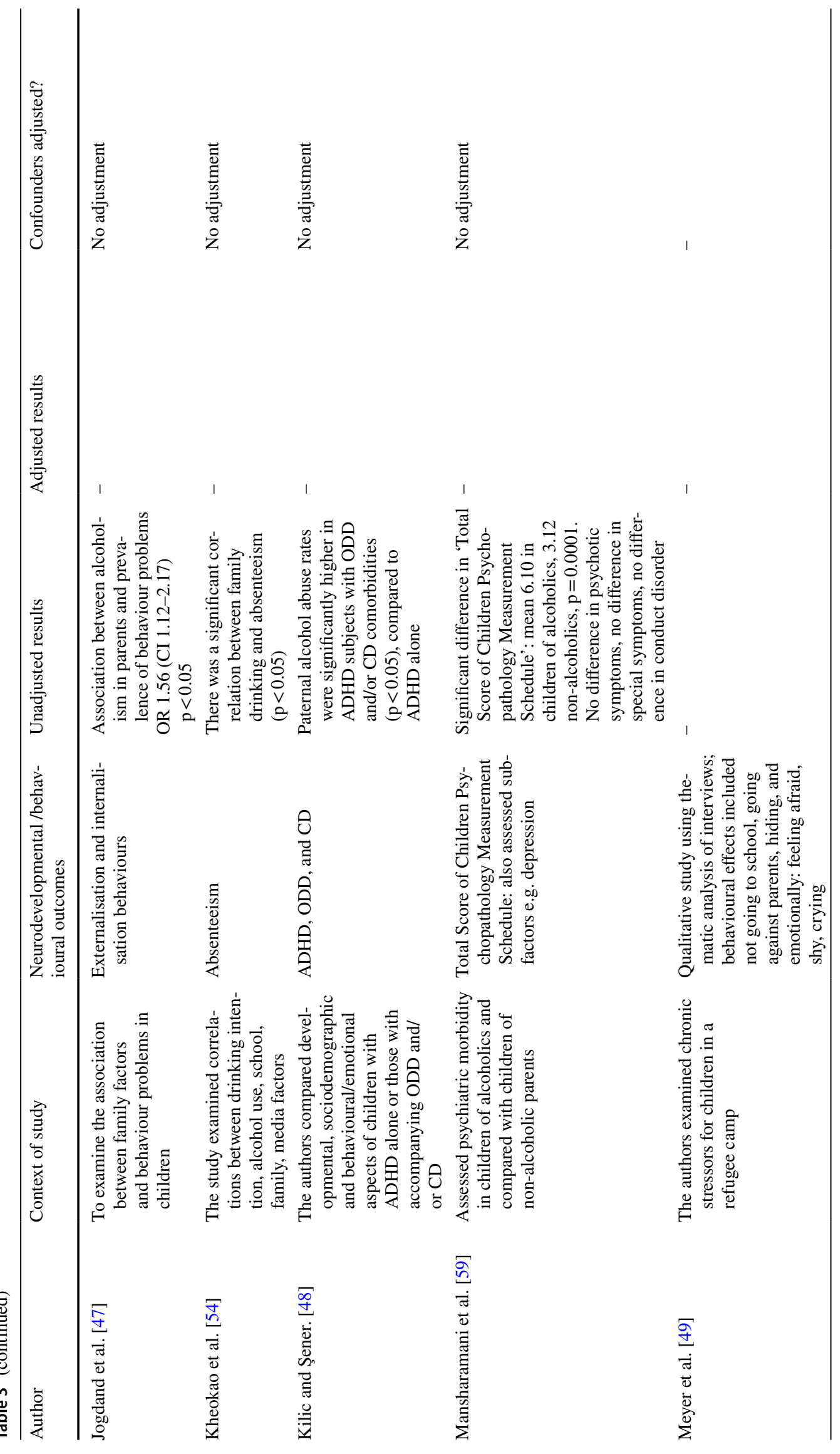




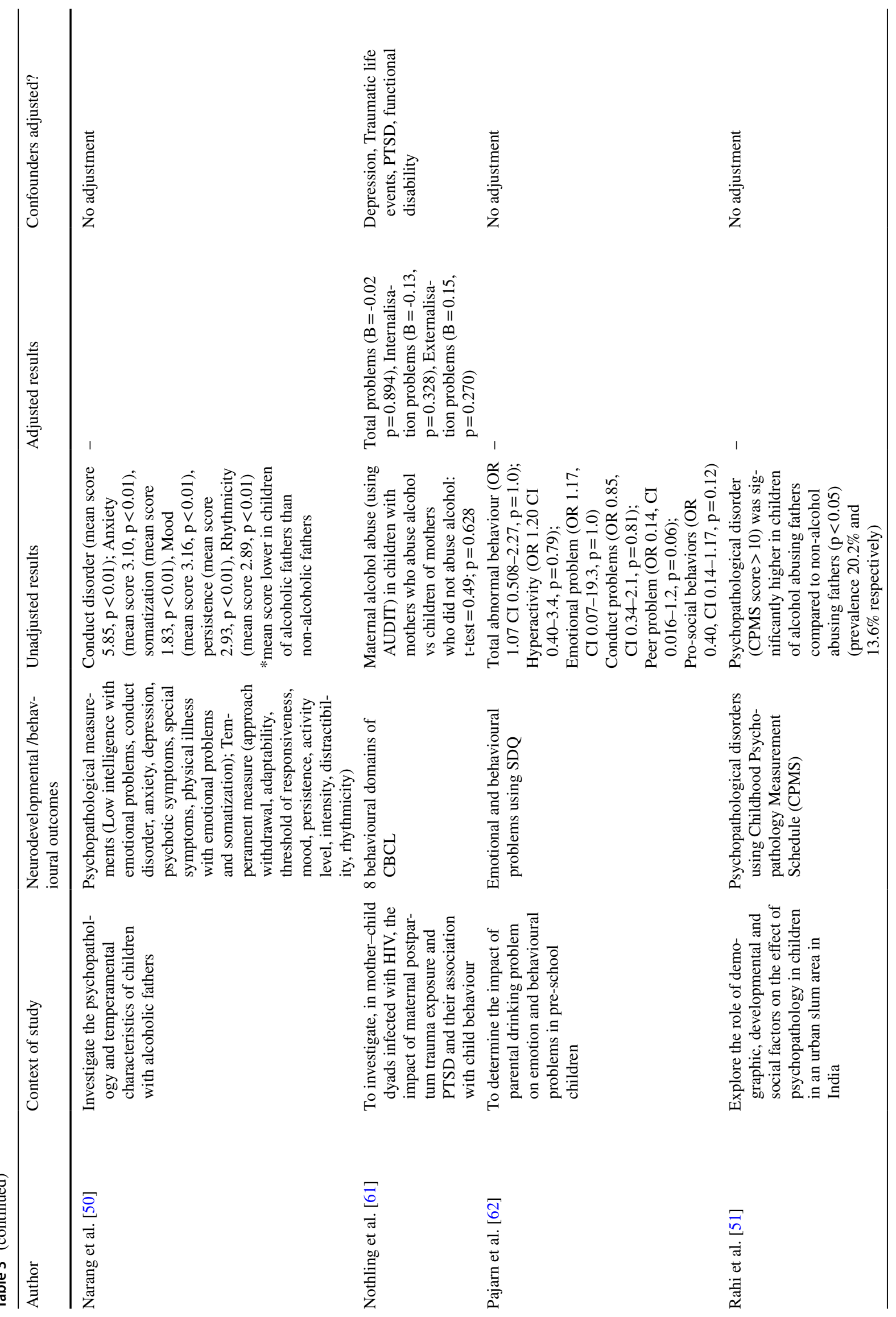




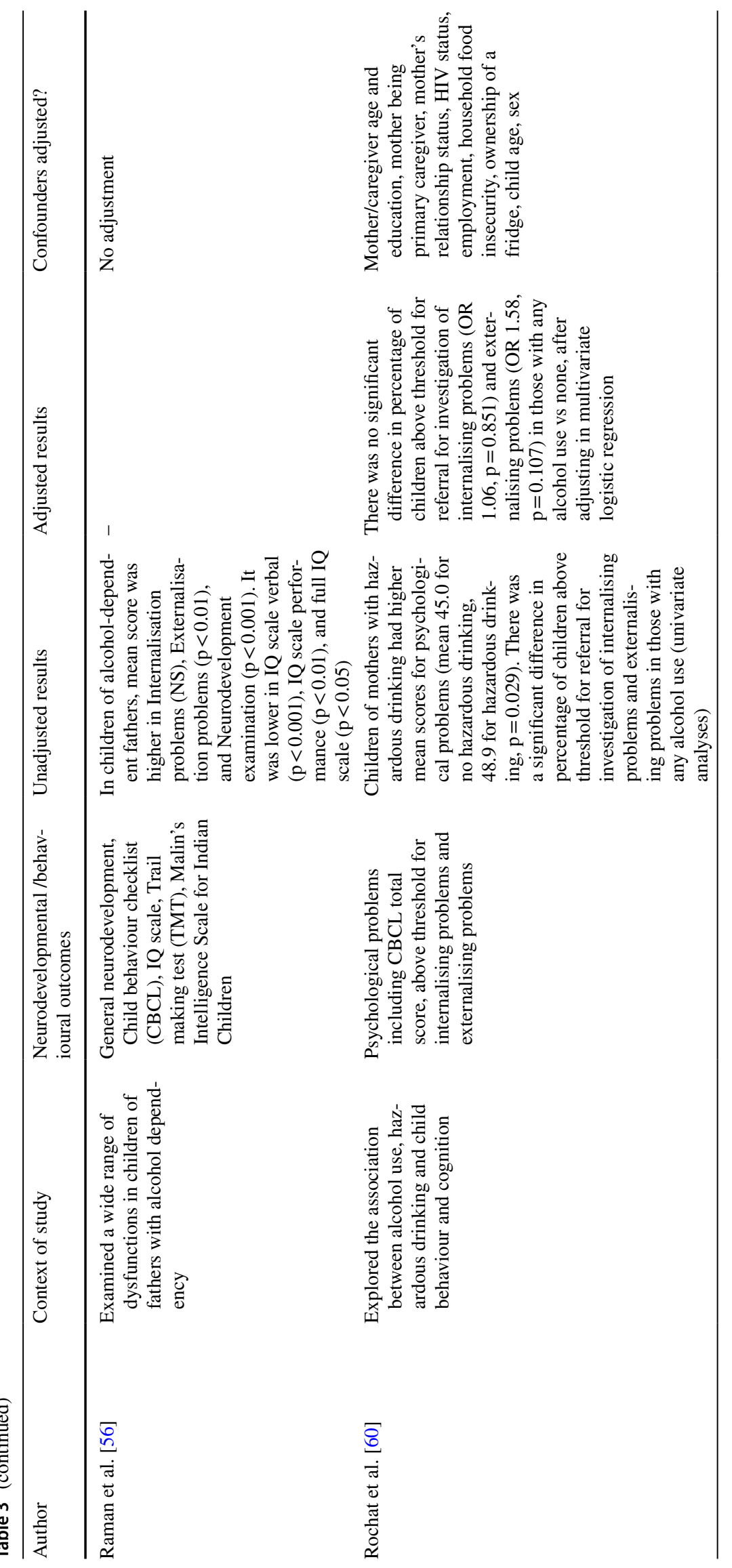




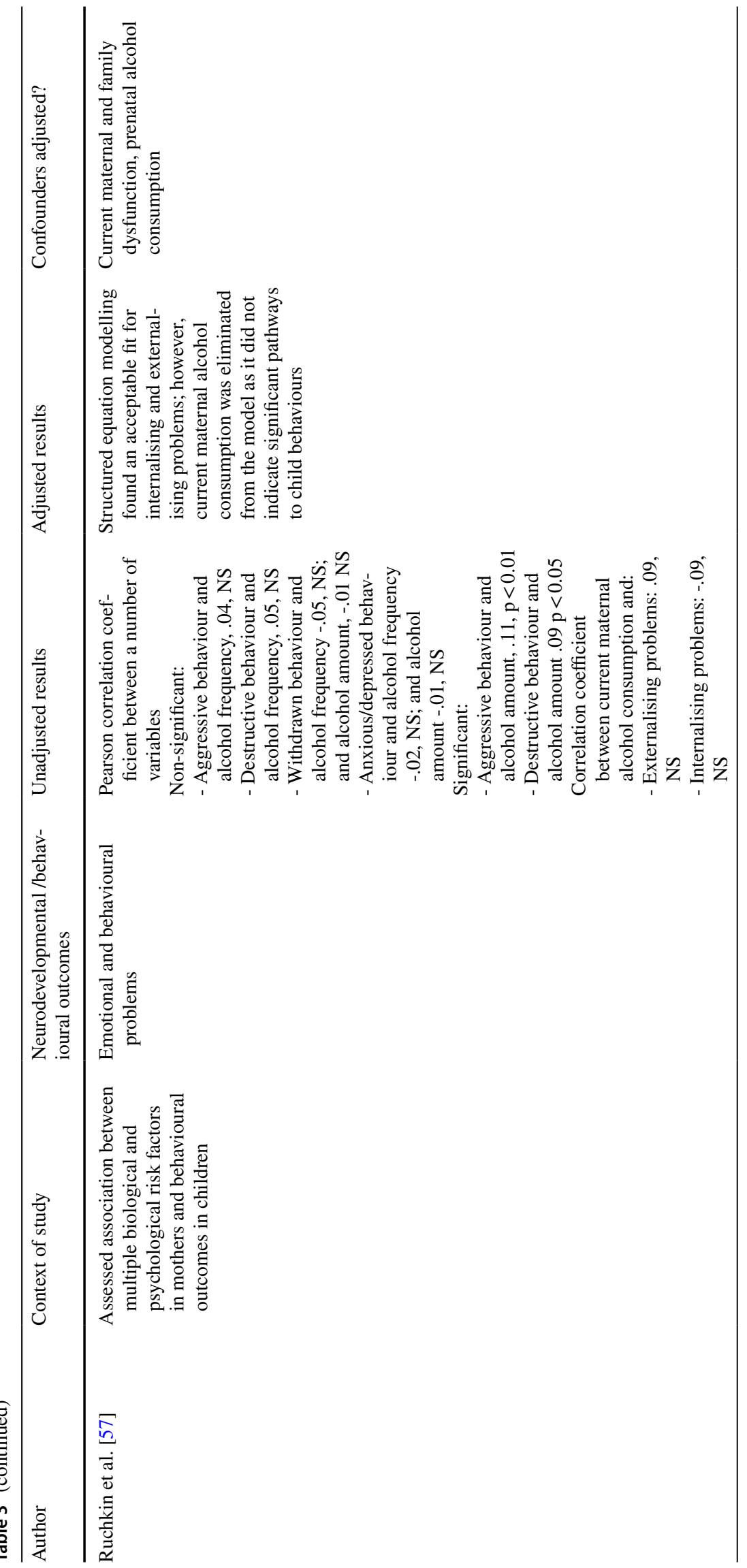




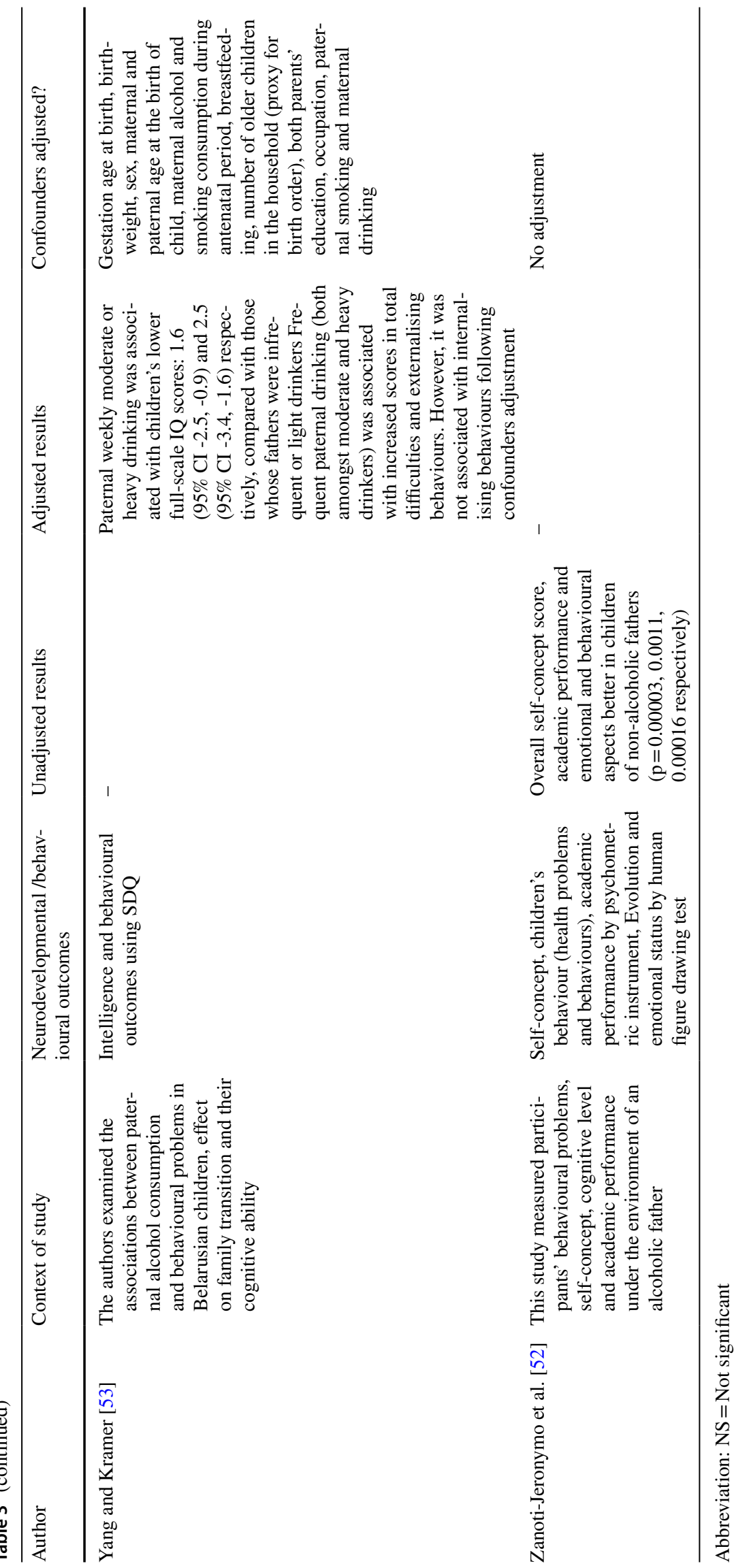


in the Ban Mai Nai Soi camp in Thailand [49]. The authors reported parental drinking led to children 'feeling upset', 'shy', 'depressed', and 'having difficulty concentrating'.

The presence of Attention Deficit Hyperactive disorder (ADHD), Oppositional Defiant Disorder (ODD), Conduct Disorder (CD), Obsessive Compulsive Disorder (OCD) were addressed by studies in Ukraine [46], Turkey [48] and India [59]. Drabick et al. (2004) found that fathers of children with ADHD more commonly abuse alcohol than fathers of children with ODD \pm ADHD in teacher defined subgroups [46]. Conversely, Kiliç and Şener (2005) found that paternal alcohol abuse was more common in children with ADHD and ODD and/or CD compared to ADHD alone [48]. However, Mansharamani et al. (2018) found no difference in scoring for OCD and Conduct disorder between children of alcoholics and children of non-alcoholics [59] (Table 3).

\section{Child Cognitive Delay or Disorder}

Eight studies $[52-54,56,59,60,71,72]$ investigated cognitive delay/disorder related to intelligence and academic performance (Table 4). Overall, most studies found an association between paternal drinking and lower performance in key academic domains and/or intelligence. Importantly, there was some indication of a dose-dependent nature of paternal alcohol consumption and child's IQ score [53].

In a cross-section study in India, which categorised 129 children into either scholastically 'backward' or 'superior', Shenoy et al. (1996) found that children who are 'scholastically backward' more commonly have fathers who drink regularly (41.94\%), compared to children who were identified as 'scholastically superior' $(23.88 \%, \mathrm{p}<0.05)$ [71]. Similarly in Brazil, authors found children of alcoholics had a overall score in an academic performance test (which included reading and arithmetic), compared to children of non-alcoholic fathers [52]. Raman et al. (2010) found, using Malin's Intelligence Scale for Indian children, mean score (93.28) for the verbal section in children of alcohol-dependent fathers was significantly lower than children of non-dependent fathers $(107.1, \mathrm{p}<0.001)$ [56]. Similar results are found in performance (Mean score 95.7 vs 108.2 respectively, $\mathrm{p}<0.01$ ) and full-scale IQ test (Mean score 96.14 vs 105.1 respectively, $\mathrm{p}<0.05$ ). The largest study addressing cognitive delay from household alcohol exposure came from a Belarusian cross-sectional study in 11,305 children aged 6.5 years-old using Wechsler Abbreviated Scales of Intelligence (WASI) [53]. It showed children whose fathers were at least weekly moderate and heavy drinkers had lower IQ scores by 1.6 points (95\% CI $-2.5--0.9)$ and 2.5 points $(95 \%$ CI $-3.4-$ 1.6), respectively, compared with fathers who were light or infrequent drinkers. Importantly the authors of this study controlled for confounders (including maternal alcohol/ smoking, parent's education, occupation, gestational age, and birth weight) (Table 4). In one MRI study sampling children with IQs $<70$, da Rocha et al. (2006) found that $62 \%$ of children with no structural brain lesion had alcoholic relatives, compared to none of the children with structural brain lesions; however there was no adjustment for confounders [72].

Among studies with mixed or negative results, Rochat et al. (2019) found that children of mothers who engaged in "hazardous drinking" (Defined as scoring $\geq 8$ on an AUDIT scale) were significantly more likely to have lower scores for learning $(p=0.017)$ and riddle solving $(p=0.045)$ using the Kaufman Assessment Battery for Children; however there was no significant effect on sequential, planning or simultaneous cognition [60]. Two other studies also found no significant impact of familial alcohol use on cognitive measures, one regarding the prevalence of 'low intelligence with behavioural problem' [59] and one on grade point average (GPA) [54].

\section{Childhood risky behaviour}

Six studies [49, 73-77] included information on childhood risky behaviour in relation to household alcohol consumption (Table 5). These risky behaviours included suicide attempts, self-harm, substance abuse/misuse and anti-social behaviour. It is important to note that since self-harm is not common in very young children, these studies primarily included subjects whose ages extended into adolescence, though they did include children less than 13-years-old (age ranges in the four main relevant studies were 10-17 [74], 11-20 [75], 9-17 [49], 11-19 [73]).

Studies in Turkey [75] and Rwanda [74] did not demonstrate an association between paternal/maternal drinking and risky behaviours amongst children (Table 5). Specifically, in the former study [75], the authors found that parental alcoholism did not significantly increase the odds of cannabis use, solvent/inhalants use and/or ecstasy use in their children. Betancourt et al. (2016) in Rwanda found 20 cases with current suicidality among 680 children, of whom only $4(20 \%)$ reported alcohol abuse in the family [74]. However, this was a methodology study and did not set out to test hypotheses directly relevant to this review (Table 5).

In China, in an unadjusted analysis, higher rates of suicide attempts were found amongst older children and adolescents (aged 11-19) in families where a family member had a problem with alcohol abuse $(4.4 \%$ vs $2.4 \%, \mathrm{p}<0.001)$ [73]. In a separate analysis, the authors modelled social problems of family members (which included gambling, alcohol abuse, and violation of law) and found these to be associated with a higher risk of self-reported suicide attempts in a model controlling for family demographics (Adjusted OR 1.27, 95\% CI 1.17-1.38, p < 0.001) and when also controlling for family lifestyle factors (OR1.25, 95\% CI 1.15-1.35, p <0.001). 


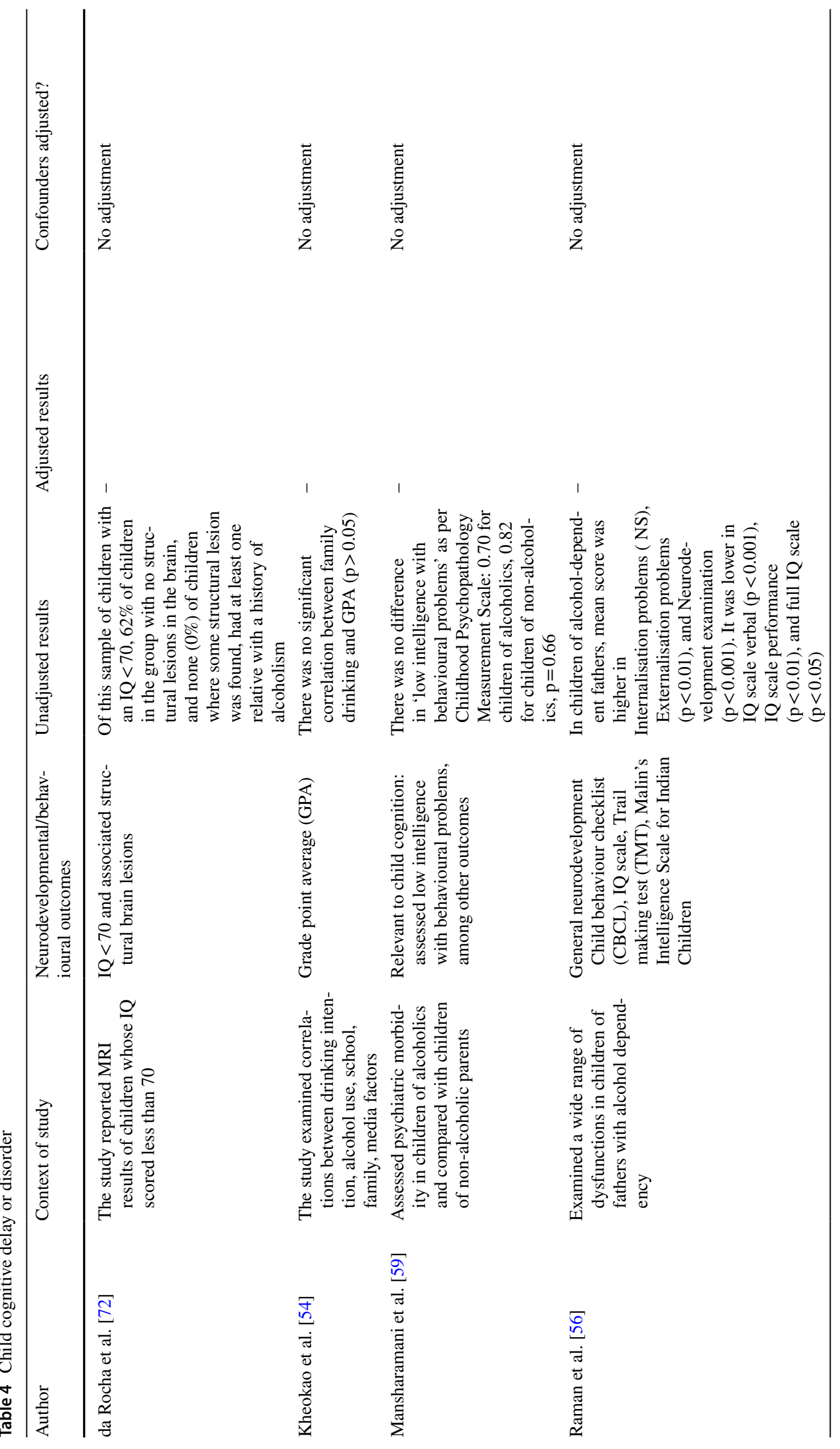




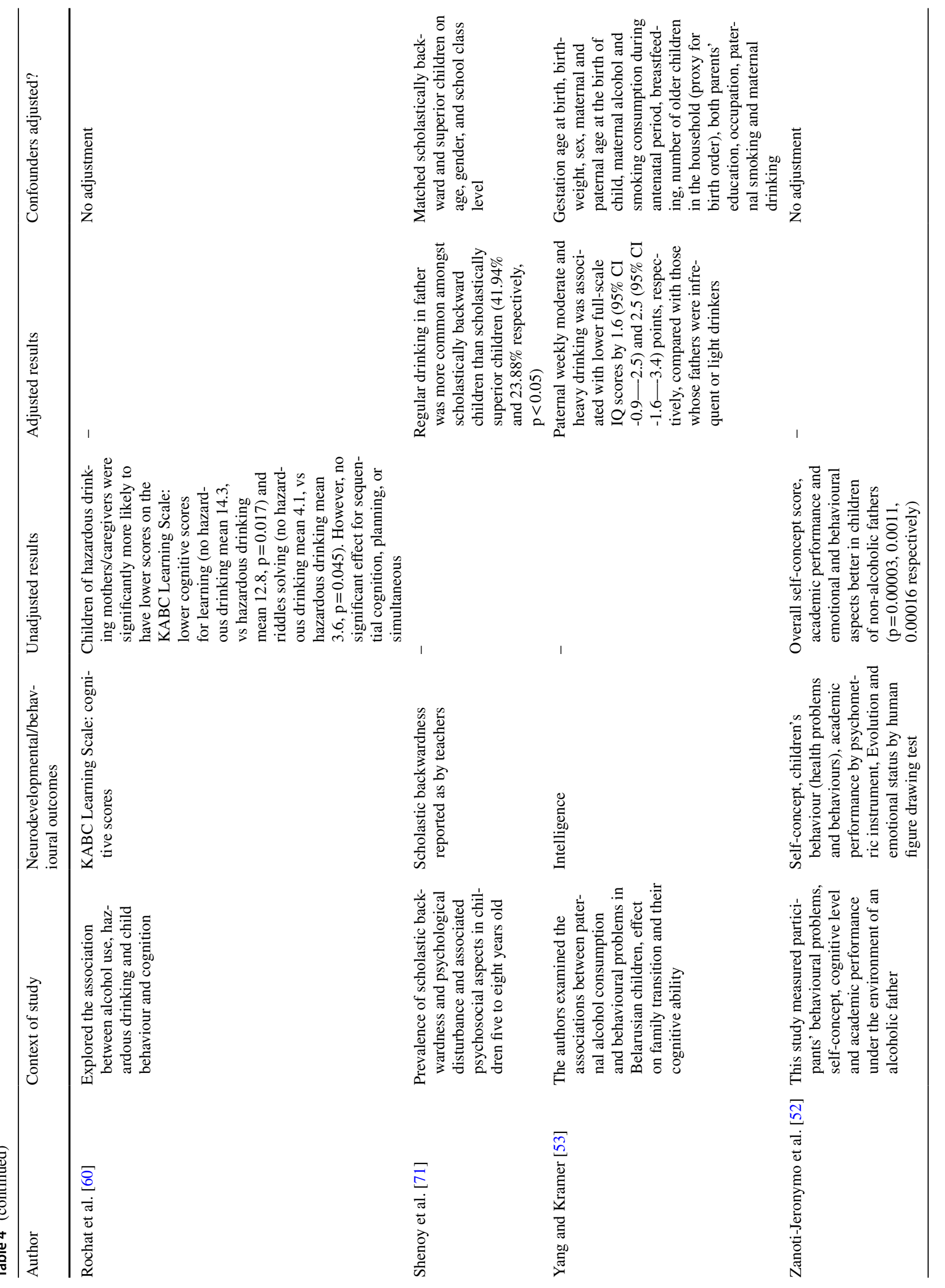




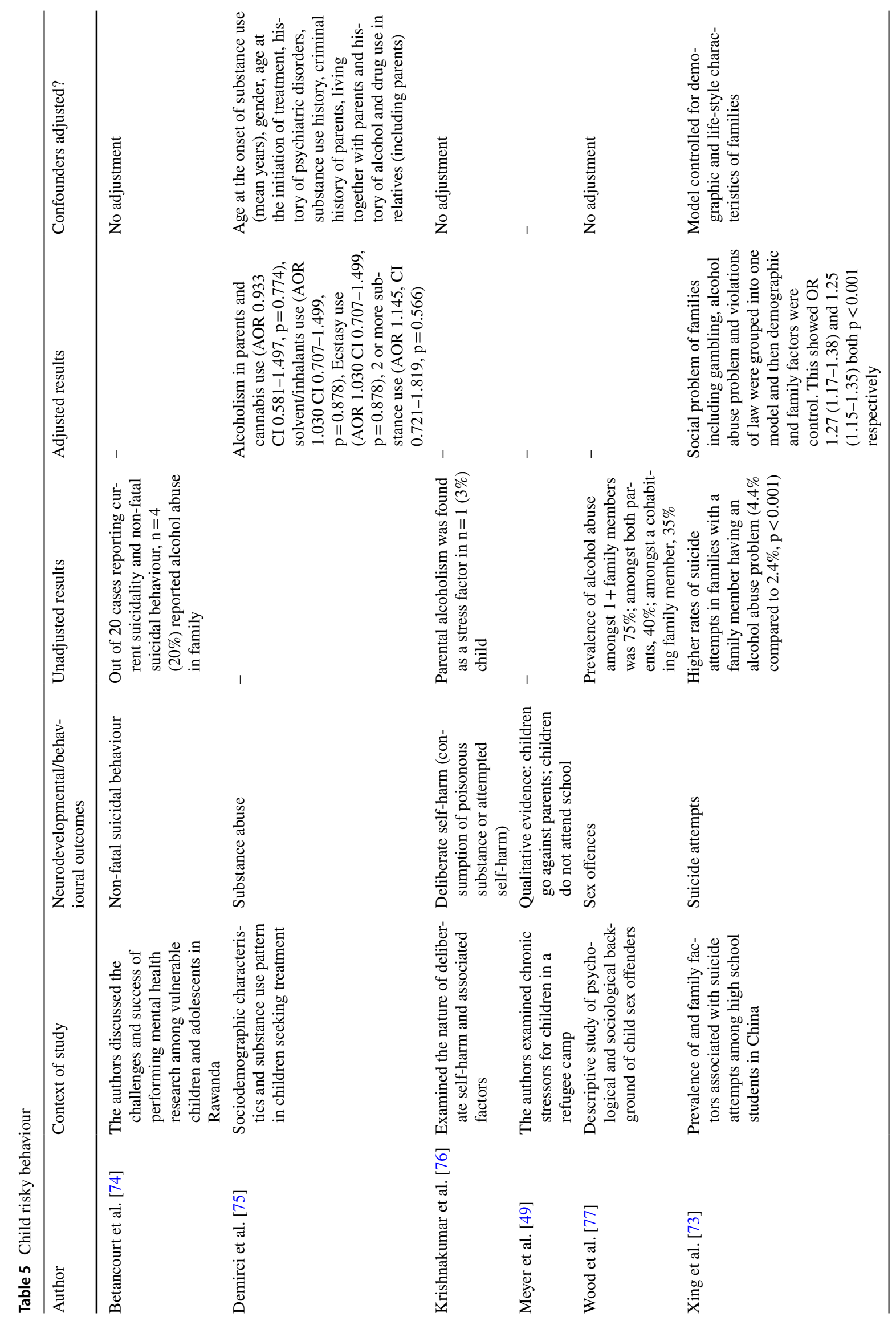


Finally, Wood et al. (2000) completed a small study $(n=20)$ of child and adolescent sex offenders, and found that the prevalence of alcohol abuse amongst one or more family members was 75\% [77]. The two other studies included a qualitative study describing alcohol as a chronic stressor, and another study where parental alcoholism was a stress factor for one child out of 29 engaging in self harm [49, 76].

\section{Other}

Raman et al. (2010) explored cultural and intellectual activity ratings among children of alcohol dependent fathers compared to children without this exposure [56]. The authors found that the children of alcoholics had significantly lower independence and intellectual/cultural orientation scores compared to controls, but this was not the case for other types of personal development scores (e.g. active/recreational scores).

Zanoti-Jeronymo et al. (2005) examined children's selfconcept by comparing 40 children of alcohol and non-alcoholic fathers [52]. The authors demonstrated that in areas of self-concept, children of non-alcoholic fathers scored significantly higher in attributes of physical appearance, happiness and satisfaction, anxiety management, intellectual status and popularity, when compared to children of alcoholic fathers. Finally, regarding depression, Mansharamani et al. (2018) found that there were significantly greater mean CPMS scores for depression $(\mathrm{p}=0.016)$, and anxiety $(p=0.02)$ in children of alcoholics compared to children of non-alcoholics [59]. However, in contrast, in a large study of 3,509 children in Malaysia, Ahmed et al. (2015) found that children exposed to parental alcohol abuse did not have higher odds of a high depression score ('CES-DC' score over 31) compared to those who were not (Adjusted OR 1.08 (95\% CI 0.65 -1.80) [78]. Pillay and van der Veen (1997) compared characteristics of admissions to a child psychiatric facility and found there was no statistically significant association between being from a substance-abusing household (93\% alcohol-implicated), and a diagnosis of depression, in a small sample in South Africa [79].

\section{Discussion}

\section{What is Already Known on this Topic}

This study contributes to the existing knowledge base on the impact of household alcohol exposure on neurodevelopmental outcomes in children, in particular children in LMICs. An important constituent of childhood growth is neurodevelopment, which includes the development of expressive and receptive language, including social communication; visual problem solving (nonverbal cognition); motor development; neurobehavioral development; and social-emotional development [80]. There are multiple factors including physiological and environmental, which can affect the normal trajectory of these developmental goals [81]. Home environment, and the people within, play a crucial role in this complex interaction [82-85]. Home environment provides nurturing ground for development, alongside adequate nutrition, education, protection from harm, abuse and neglect and good healthcare. However, it can also introduce experiences which may affect a child's neurodevelopment and behaviour concurrently and which can endure into adulthood.

From studies based in high income countries, we know that exposure to parental alcohol abuse can cause profound cognitive, behavioural, emotional and other social problems in children [86-88]. Additionally, in terms of cognitive delay or dysfunction, a number of studies have shown that improvements in social supportive environments can result in subsequent improvements in cognitive scoring; low scores can reflect a non-supportive environment as much as any individual innate difficulty [89-91]. However, not all children with the same exposure to negative experiences, such as alcohol abuse within a household, may have an equal risk of developing a behavioural problem, with studies indicating a genetic influence on propensity towards certain behaviours [92, 93]. It is important to consider alcohol exposure in low- and middle-income countries as a separate entity, because the settings for studies conducted in high-income countries may be significantly different in terms of alcohol availability, drinking culture, family environment, family members, household locations (e.g. slums), poverty, and violence; these can all influence levels of alcohol exposure. The root cause of alcohol abuse in a household is also an important factor to consider. Numerous studies suggested that parental alcohol misuse might be a coping mechanism for dealing with family dysfunction and their own childhood exposure to life stress, such as child abuse [94, 95]. Thus, the underlying reason for negative childhood outcomes could be due to the presence of broader family dysfunction, with parental alcohol misuse acting more as a surrogate marker than a direct cause.

Family environment is a complex social environment with multiple adverse or protective issues at play. Adverse influences include loss or absence of a parent, job loss leading to leading to financial difficulties, poverty or low socio-economic status, neglect, household substance misuse including alcohol, and parental or family conflict and discord. By conceptualising family environment as a dynamic system, whereby change in behaviour in one element of the system impacts and causes compensatory changes by other family members, it can also be seen how children may adapt their behaviours, some of which may place them at risk, if a family member is absent or performing poorly due to alcohol abuse [96]. 


\section{What this Study Adds}

To our knowledge, this is the first attempt to systematically review evidence regarding household alcohol exposure and its impact on neurodevelopmental outcomes in children in low- and middle-income countries. Despite heterogeneity in exposure and in settings, we report an overall association between household harmful use of alcohol and a number of negative neurodevelopmental outcomes in children, including behaviour problems, cognitive impairment and performance, fewer cultural/intellectual activities and low self-concept. However, evidence of an association between household alcohol misuse and risky behaviours was limited to studies which included a preponderance of adolescents.

Despite this observed association, household alcohol exposure has not been established as an independent risk factor for poor childhood neurodevelopmental outcomes. Only a handful of studies accounted for confounders such as parental depression, traumatic life events experienced by the household, financial problems, or childhood factors such as poor nutrition, premature birth, and intrauterine toxin exposure. Amongst the studies which adjusted for confounders, varied outcomes were investigated. In addition, the optimal method for drawing causal inferences regarding the role of household alcohol exposure should be through the use of well-designed prospective cohort studies; retrospective measures may be more vulnerable to bias [97]. In this review only three relatively small studies $[48,61,76]$ were designed in this way. Future studies should establish temporal relationships between exposure and outcomes and adjust for confounders.

\section{Limitations in the Research Literature}

\section{Measurement of Alcohol Use}

Loose definitions of 'alcohol abuse' or 'problem drinking' were used in many studies to compare outcomes with no quantification of what this might amount to. A range of tools have been reported- from standardised tools (e.g. AUDIT) to uncorroborated self-reports of alcohol abuse. The absence of uniform and quantifiable or clear functional measures of alcohol misuse precluded a comparison between studies. Consequently, it has not been possible to identify whether or not there is a level of household alcohol use or type of alcohol disorder or a dose response relationship that might constitute a risk to the behavior or development of their children. The nature of exposure to household alcohol was also poorly defined in the included studies. There was little indication of the extent to which children were directly exposed either to drinking or drunkenness; it was not clear whether alcohol use mostly occurred at home in the children's presence or outside the house. During assessment of full texts, it was noted that several of the studies matching our search terms were wholly or simultaneously addressing antenatal drinking. Since maternal antenatal drinking can have profound pathophysiological impact on the developing fetus, studies of maternal alcohol use should differentiate prenatal and postnatal exposure or clearly stratify results by timing of alcohol exposure.

\section{Research Implications}

The heterogeneity in the results and the methodological challenges discovered necessitate that more studies be undertaken, with clearly defined neurodevelopmental outcomes and careful quantification of household alcohol use in order that more accurate conclusions can be drawn. In studies including a wide age range, the results should be stratified by age.

Further research also needs to be done to explore the mechanisms through which child neurodevelopmental outcomes might arise, and to elucidate the role of household alcohol use within these. Key covariates which could confound the relationship between household alcohol misuse and childhood behavioural or developmental disorders should be adjusted for. Furthermore, longitudinal studies could provide vital data on the temporal nature in which neurodevelopment is affected by household alcohol misuse, and thus could provide key information for appropriate interventional strategies.

\section{Limitations of this Review}

Ultimately the strength of the conclusions of this review are limited by the methodological issues identified in the included papers. Due to the heterogeneous natures of the studies, we have carried out a narrative rather than a quantitative synthesis. This review only included studies which were published after 1990. Including only studies available in English meant that some potentially important studies could not be considered.

\section{Summary}

This review shows that exposure to alcohol misuse by household members in the context of low- and middle-income countries is associated with adverse child neurodevelopmental outcomes, although causal inferences cannot be drawn in the absence of well conducted prospective cohort studies which address potential confounding. Nevertheless, the association was seen across a wide range of countries, in both urban and rural environments. Results were heterogeneous, which may be related to our observation that the types of alcohol misuse and the frequency and amounts of alcohol 
use were poorly quantified in many studies. Statistically significant correlations were demonstrated between paternal alcohol misuse and child problem behaviours, cognitive delay, and risky behaviours. In contrast, the association with maternal drinking was less well studied.

Author Contributions LLD and LM conceived of and led the review. TH developed the protocol and performed initial searches, supervised by EA. TJ and TH undertook the majority of the screening and data extraction, supervised and assisted by EA. PT, ID and DB contributed to the screening and data extraction. EA and PP undertook the 2020 search, extraction and update. TH wrote the first draft of the review and EA, LLD, LM and TJ provided the majority of further contributions to refining the draft and producing the final manuscript. EA and TH led manuscript revisions. All authors contributed to and approved the final version of the manuscript.

Funding Logan Manikam is funded by a UK National Institute for Health Research Advanced Fellowship (Ref: NIHR300020) and is Director of Aceso Global Health Consultants Limited. The research work by Davidson PI reported in this publication was supported in part by the National Institutes of Health, Fogarty International Center, National Institutes of Health, and Office of Behavioral and Social Sciences Research, Office of Disease Prevention under award number R01-TW011228. The content is solely the responsibility of the authors and does not necessarily represent the official views of the National Institutes of Health.

\section{Compliance with Ethical Standards}

Conflict of interest Logan Manikam is funded by a UK National Institute for Health Research Advanced Fellowship (Ref: NIHR300020) and is Director of Aceso Global Health Consultants Limited. The research work by Davidson PI reported in this publication was supported in part by the National Institutes of Health, Fogarty International Center, National Institutes of Health, and Office of Behavioral and Social Sciences Research, Office of Disease Prevention under award number R01-TW011228. The content is solely the responsibility of the authors and does not necessarily represent the official views of the National Institutes of Health.

Ethical Approval All procedures performed in this study were in accordance with the ethical standards of the institution of the authors and with the 1964 Helsinki declaration and its later amendments or comparable ethical standards. This study was registered in PROSPERO, CRD42017070209. This article does not contain any studies with human participants or animals performed by any of the authors.

Informed Consent Informed consent is not applicable as this article is a review.

Open Access This article is licensed under a Creative Commons Attribution 4.0 International License, which permits use, sharing, adaptation, distribution and reproduction in any medium or format, as long as you give appropriate credit to the original author(s) and the source, provide a link to the Creative Commons licence, and indicate if changes were made. The images or other third party material in this article are included in the article's Creative Commons licence, unless indicated otherwise in a credit line to the material. If material is not included in the article's Creative Commons licence and your intended use is not permitted by statutory regulation or exceeds the permitted use, you will need to obtain permission directly from the copyright holder. To view a copy of this licence, visit http://creativecommons.org/licenses/by/4.0/.

\section{References}

1. Mersky JP, Topitzes J, Reynolds AJ (2013) Impacts of adverse childhood experiences on health, mental health, and substance use in early adulthood: a cohort study of an urban, minority sample in the U.S. Child Abuse Negl. 37(11):917-925

2. Giglio JJ, Kaufman E (1990) The relationship between child and adult psychopathology in children of alcoholics. Int $\mathbf{J}$ Addict 25(3):263-290

3. Korhonen T, Huizink A, Dick D, Pulkkinen L, Rose R, Kaprio J (2008) Role of individual, peer and family factors in the use of cannabis and other illicit drugs: A longitudinal analysis among Finnish adolescent twins. Drug Alcohol Depend 97(1-2):33-43

4. Hughes K, Lowey H, Quigg Z, Bellis MA (2016) Relationships between adverse childhood experiences and adult mental wellbeing: results from an English national household survey. BMC Public Health 16:222

5. Felitti VJ, Anda RF, Nordenberg D, Williamson D, Spitz AM, Edwards V et al (1998) Relationship of Childhood Abuse and Household Dysfunction to Many of the Leading Causes of Death in Adults: The Adverse Childhood Experiences (ACE) Study. Am J Prev Med 14(4):245-258

6. Bellis MA, Hughes K, Leckenby N, Hardcastle KA, Perkins C, Lowey H (2015) Measuring mortality and the burden of adult disease associated with adverse childhood experiences in England: a national survey. J Public Health (Oxf). 37(3):445-454

7. Bellis MA, Lowey H, Leckenby N, Hughes K, Harrison D (2014) Adverse childhood experiences: retrospective study to determine their impact on adult health behaviours and health outcomes in a UK population. J Public Health (Bangkok) 36(1):81-91

8. Anda RF, Dong M, Brown DW, Felitti VJ, Giles WH, Perry GS et al (2009) The relationship of adverse childhood experiences to a history of premature death of family members. BMC Public Health 16(9):106

9. Brown DW, Anda RF, Tiemeier H, Felitti VJ, Edwards VJ, Croft JB et al (2009) Adverse Childhood Experiences and the Risk of Premature Mortality. Am J Prev Med 37(5):389-396

10. Berent D, Podgórski M, Kokoszka A (2018) A need for intervention: Childhood adversities are asignificant determinant of healthharming behavior and poor self-efficacy in patients with alcohol dependence. An observational, cross-sectional study on the population of Central Poland. Adv Clin Exp Med 27(9):1271-1277

11. Berent D, Wojnar M (2020) The role of adverse childhood experiences in risky behaviors, health care utilization, and generalized self-efficacy in the general adult Polish population. Arch Med Sci. https://doi.org/10.5114/aoms.2020.96343

12. van Duin L, Bevaart F, Zijlmans J, Luijks M-JA, Doreleijers TAH, Wierdsma AI et al (2019) The role of adverse childhood experiences and mental health care use in psychological dysfunction of male multi-problem young adults. Eur Child Adolesc Psychiatry. 28(8):1065-1078

13. Anda RF, Whitfield CL, Felitti VJ, Chapman D, Edwards VJ, Dube SR et al (2002) Adverse childhood experiences, alcoholic parents, and later risk of alcoholism and depression. Psychiatr Serv 53(8):1001-1009

14. Schilling EA, Aseltine RH, Gore S (2007) Adverse childhood experiences and mental health in young adults: a longitudinal survey. BMC Public Health 7(1):30

15. Thompson MP, Kingree JB, Lamis D (2019) Associations of adverse childhood experiences and suicidal behaviors in adulthood 
in a U.S. nationally representative sample. Child Care Health Dev. 45(1):121-128

16. Davidson LL, Grigorenko EL, Boivin MJ, Rapa E, Stein A (2015) A focus on adolescence to reduce neurological, mental health and substance-use disability. Nature 527:S161

17. Blum RW, Bastos FIPM, Kabiru CW, Le LC (2012) Adolescent health in the 21st century. Lancet 379(9826):1567-1568

18. Hughes K, Bellis MA, Hardcastle KA, Sethi D, Butchart A, Mikton $C$ et al (2017) The effect of multiple adverse childhood experiences on health: a systematic review and meta-analysis. Lancet Public Heal 2(8):e356-e366

19. Weinberg NZ (1997) Cognitive and Behavioral Deficits Associated With Parental Alcohol Use. J Am Acad Child Adolesc Psychiatry 36(9):1177-1186

20. Marmorstein NR, Iacono WG, McGue M (2009) Alcohol and illicit drug dependence among parents: associations with offspring externalizing disorders. Psychol Med 39(1):149-455

21. Hussong AM, Huang W, Curran PJ, Chassin L, Zucker RA (2010) Parent alcoholism impacts the severity and timing of children's externalizing symptoms. J Abnorm Child Psychol 38(3):367-380

22. Flaherty EG, Thompson R, Dubowitz H, Harvey EM, English DJ, Proctor LJ et al (2013) Adverse childhood experiences and child health in early adolescence. JAMA Pediatr 167(7):622-629

23. Lengua LJ, Thompson SF, Moran LR, Zalewski M, Ruberry EJ, Klein MR et al (2019) Pathways from early adversity to later adjustment: Tests of the additive and bidirectional effects of executive control and diurnal cortisol in early childhood. Dev Psychopathol 2019(05/10):1-14

24. Ruggles S, Heggeness M (2008) Intergenerational Coresidence in Developing Countries. Popul Dev Rev 34(2):253-281

25. Bongaarts J, Zimmer Z (2002) Living Arrangements of Older Adults in the Developing World: An Analysis of Demographic and Health Survey Household Surveys. J Geronotology Soc Sci 57B(3):S145-S157

26. Brown TT, Jernigan TL (2012) Brain development during the preschool years. Neuropsychol Rev. 22(4):313-333

27. McEwen BS (2012) Brain on stress: How the social environment gets under the skin. Proc Natl Acad Sci. 109(2):17180-17185

28. McLaughlin KA, Sheridan MA, Lambert HK (2014) Childhood adversity and neural development: deprivation and threat as distinct dimensions of early experience. Neurosci Biobehav Rev 47:578-591

29. Roth TL, Lubin FD, Funk AJ, Sweatt JD (2009) Lasting epigenetic influence of early-life adversity on the BDNF gene. Biol Psychiatry. 65(9):760-769

30. Hanson JL, Nacewicz BM, Sutterer MJ, Cayo AA, Schaefer SM, Rudolph KD et al (2015) Behavioral problems after early life stress: contributions of the hippocampus and amygdala. Biol Psychiatry. 77(4):314-323

31. Lenroot RK, Giedd JN (2006) Brain development in children and adolescents: insights from anatomical magnetic resonance imaging. Neurosci Biobehav Rev 30(6):718-729

32. Konrad K, Firk C, Uhlhaas PJ (2013) Brain development during adolescence: neuroscientific insights into this developmental period. Dtsch Arztebl Int. 110(25):425-431

33. Giedd JN, Blumenthal J, Jeffries NO, Castellanos FX, Liu H, Zijdenbos A et al (1999) Brain development during childhood and adolescence: a longitudinal MRI study. Nat Neurosci 2:861

34. Blakemore S-J, Burnett S, Dahl RE (2010) The role of puberty in the developing adolescent brain. Hum Brain Mapp 31(6):926-933

35. Jokinen T, Alexander EC, Manikam L, Huq T, Patil P, Benjumea D et al (2020) A Systematic Review of Household and Family Alcohol Use and Adolescent Behavioural Outcomes in Low- and Middle-Income Countries. Child Psychiatry Hum Dev. https://doi. org/10.1007/s10578-020-01038-w
36. The World Bank. The World Bank: Low \& middle income [Internet]. The World Bank: Data. 2018. Available from: https://data. worldbank.org/income-level/low-and-middle-income

37. World Health Organization (WHO). International Classification of Disease (ICD)- 11th Revision. 2018.

38. The Cochrane Library. LMIC Filters [Internet]. 2017 [cited 2017 Jul 1]. Available from: http://epoc.cochrane.org/lmic-filters

39. Puchalski Ritchie LM, van Lettow M, Hosseinipour MC, Rosenberg NE, Phiri S, Landes M et al (2015) The effectiveness of interventions to improve uptake and retention of HIV-infected pregnant and breastfeeding women and their infants in prevention of mother-to-child transmission care programs in low- and middleincome countries: protocol for a systemati. Syst Rev 4(1):144

40. Khatib R, Arevalo YA, Berendsen MA, Prabhakaran S, Huffman MD (2018) Presentation, Evaluation, Management, and Outcomes of Acute Stroke in Low- and Middle-Income Countries: A Systematic Review and Meta-Analysis. Neuroepidemiology 51(1-2):104-112

41. Hansoti B, Kelen GD, Quinn TC, Whalen MM, DesRosiers TT, Reynolds SJ et al (2017) A systematic review of emergency department based HIV testing and linkage to care initiatives in low resource settings. PLoS ONE 12(11):e0187443

42. Siriwardhana DD, Hardoon S, Rait G, Weerasinghe MC, Walters KR (2018) Prevalence of frailty and prefrailty among community-dwelling older adults in low-income and middle-income countries: a systematic review and meta-analysis. BMJ Open 8(3): 018195

43. NICE. NICE Glossary [Internet]. National Institute of Clinical Excellence (NICE). 2017 [cited 2017 Apr 1]. Available from: https://www.nice.org.uk/glossary

44. National Heart Lung and Blood Institute (NHLBI). Study Quality Assessment Tools [Internet]. Study Quality Assessment Tools. 2020 [cited 2020 May 10]. Available from: https://www.nhlbi.nih. gov/health-topics/study-quality-assessment-tools

45. Bele SD, Bodhare TN, Valsangkar S, Saraf A (2013) An epidemiological study of emotional and behavioral disorders among children in an urban slum. Psychol Health Med 18(2):223-232

46. Drabick DAG, Gadow KD, Carlson GA, Bromet EJ (2004) ODD and ADHD Symptoms in Ukrainian Children: External Validators and Comorbidity. J Am Acad Child Adolesc Psychiatry 43(6):735-743

47. Jogdand SS, Naik J (2014) Study of family factors in association with behavior problems amongst children of 6-18 years age group. Int J Appl basic Med Res 4(2):86-89

48. Kiliç BG, Sener S (2005) Family functioning and psychosocial characteristics in children with attention deficit hyperactivity disorder with comorbid oppositional defiant disorder or conduct disorder. Turk Psikiyatri Derg 16(1):21-28

49. Meyer S, Murray LK, Puffer ES, Larsen J, Bolton P (2013) The nature and impact of chronic stressors on refugee children in Ban Mai Nai Soi camp. Thailand Glob Public Health 8(9):1027-1047

50. Narang RL, Gupta R, Mishra BP, Mahajan R (1997) Temperamental characteristics and psychopathology among children of alcoholics. Indian J Psychiatry 39(3):226-231

51. Rahi M, Kumavat AP, Garg S, Singh MM (2005) Socio-demographic co-relates of psychiatric disorders. Indian J Pediatr 72(5):395-398

52. Zanoti-Jeronymo DV, Carvalho AMP (2005) Self-concept, academic performance and behavioral evaluation of the children of alcoholic parents. Rev Bras Psiquiatr 27(3):233-236

53. Yang S, Kramer MS (2012) Paternal alcohol consumption, family transition and child development in a former Soviet country. Int J Epidemiol 41(4):1086-1096

54. Kheokao JK, Kirkgulthorn T, Yingrengreung S, Singhprapai P (2013) Effects of School, Family and Alcohol Marketing 
Communication on Alcohol Use and Intentions to Drink among Thai Students. Southeast Asian J Trop Med Public Heal 44(4):718-726

55. Jardin C, Marais L, Bakhshaie J, Skinner D, Neighbors C, Zvolensky $M$ et al (2017) Caregiver alcohol use and mental health among children orphaned by HIV/AIDS in South Africa. AIDS Care 29(3):399-407

56. Raman V, Prasad S, Appaya MP (2010) Children of men with alcohol dependence: Psychopathology, neurodevelopment and family environment. Indian J Psychiatry 52(4):360-366

57. Ruchkin V, Gilliam WS, Mayes L (2008) Developmental pathway modeling in considering behavior problems in young Russian children. Child Psychiatry Hum Dev 39(1):49-66

58. Chander P, Kvalsvig J, Mellins CA, Kauchali S, Arpadi SM, Taylor $\mathrm{M}$ et al (2017) Intimate Partner Violence and Child Behavioral Problems in South Africa. Pediatrics. https://doi.org/10.1542/ peds.2016-1059

59. Mansharamani H, Patil PS, Behere PB, Mansharamani D, Nagdive A (2018) Psychiatric morbidity in children of alcoholic parents. Ind Psychiatry J 27(2):226-230

60. Rochat TJ, Houle B, Stein A, Mitchell J, Bland RM (2019) Maternal alcohol use and children's emotional and cognitive outcomes in rural South Africa. South African Med Journal. https://doi.org/10.7196/ SAMJ.2019.v109i7.13120

61. Nothling J, Martin CL, Laughton B, Cotton MF, Seedat S (2013) Maternal post-traumatic stress disorder, depression and alcohol dependence and child behaviour outcomes in mother-child dyads infected with HIV: a longitudinal study. BMJ Open 3(12):e003638

62. Pajarn P, Theeranate C (2012) Impact of parental alcohol consumption on emotional and behavioral problems in children age 3-4 years. J Med Assoc Thai 95(Suppl 5):S6-11

63. Burlaka V, Kim YJ, Crutchfield JM, Lefmann TA, Kay ES (2017) Predictors of internalizing behaviors in ukrainian children. Fam Relations An Interdiscip J Appl Fam Stud 66(5):854-866

64. Goodman R (1997) The Strengths and Difficulties Questionnaire: a research note. J Child Psychol Psychiatry 38(5):581-586

65. Ford T, Hutchings J, Bywater T, Goodman A, Goodman R (2009) Strengths and Difficulties Questionnaire Added Value Scores: evaluating effectiveness in child mental health interventions. Br J Psychiatry 194(06):552-558

66. Calkins SD, Dedmon SE (2000) Physiological and behavioral regulation in two-year-old children with aggressive/destructive behavior problems. J Abnorm Child Psychol 28(2):103-118

67. Gross D, Fogg L, Young M, Ridge A, Cowell JM, Richardson R et al (2006) The equivalence of the Child Behavior Checklist/1 1/2-5 across parent race/ethnicity, income level, and language. Psychol Assess 18(3):313-323

68. Mesman J, Bongers IL, Koot HM (2001) Preschool Developmental Pathways to Preadolescent Internalizing and Externalizing Problems. J Child Psychol Psychiat 42(5):679-689

69. Cooper PJ, Tomlinson M, Swartz L, Woolgar M, Murray L, Molteno C (1999) Post-partum depression and the mother-infant relationship in a South African peri-urban settlement. Br J Psychiatry 175:554-558

70. Malhotra S, Varma VK, Verma SK, Malhotra A (1988) Childhood psychopathology measurement schedule: development and standardization. Indian J Psychiatry 30(4):325-331

71. Shenoy J, Kapur M (1996) Prevalence of scholastic backwardness among five to eight year old children. Indian J Psychiatry 38(4):201-207

72. da Rocha AF, da Leite C, Rocha FT, Massad E, Cerri GG, de Angelotti SA et al (2006) Mental retardation: a MRI study of 146 Brazilian children. Arq Neuropsiquiatr 64:186-192

73. Xing XY, Tao FB, Wan YH, Xing C, Qi XY, Hao JH et al (2010) Family Factors Associated With Suicide Attempts Among Chinese
Adolescent Students: A National Cross-Sectional Survey. J Adolesc Heal 46(6):592-599

74. Betancourt T, Smith Fawzi MC, Stevenson A, Kanyanganzi F, Kirk C, Ng L et al (2016) Ethics in community-based research with vulnerable children: Perspectives from Rwanda. PLoS ONE. https:// doi.org/10.1371/journal.pone.0157042

75. Demirci AC, Erdoğan A, Yalçın O, Yıldızhan E, Koyuncu Z, Eseroğlu T et al (2014) Sociodemographic characteristics and drug abuse patterns of adolescents admitted for substance use disorder treatment in Istanbul. Am J Drug Alcohol Abuse 30(3):1-8

76. Krishnakumar P, Geeta MG, Riyaz A (2011) Deliberate self harm in children. Indian Pediatr 48(5):367-371

77. Wood C, Welman M, Netto L (2000) A profile of young sex offenders in South Africa. South African J Child Adolesc Ment Heal 12(1):45-58

78. Ahmed A, Wan-Yuen C, Marret MJ, Guat-Sim C, Othman S, Chinna K (2015) Child Maltreatment Experience among Primary School Children: A Large Scale Survey in Selangor State. Malaysia PLoS One. https://doi.org/10.1371/journal.pone.0119449

79. Pillay AL, van der Veen MB (1997) Prevalence of parental substance-abuse among child psychiatric inpatients. Percept Mot Skills 84(3 Pt 1):947-953

80. Petersen MC, Kube DA, Palmer FB (1998) Classification of developmental delays. Semin Pediatr Neurol 5(1):2-14

81. Caspi A, Moffitt TE (2006) Gene-environment interactions in psychiatry: joining forces with neuroscience. Nat Rev Neurosci 7(7):583-590

82. Yeates KO, MacPhee D, Campbell FA, Ramey CT (1983) Maternal IQ and home environment as determinants of early childhood intellectual competence: A developmental analysis. Dev Psychol 19(5):731-739

83. Earls F, Jung KG (1987) Temperament and home environment characteristics as causal factors in the early development of childhood psychopathology. J Am Acad Child Adolesc Psychiatry 26(4):491-498

84. Bradley RH, Caldwell BM, Rock SL (1988) Home Environment and School Performance: A Ten-Year Follow-Up and Examination of Three Models of Environmental Action. Child Dev 59(4):852

85. Burt SA, McGue M, Krueger RF, Iacono WG (2005) Sources of covariation among the child-externalizing disorders: informant effects and the shared environment. Psychol Med 35(8):1133-1144

86. Schuckit MA, Smith TL, Pierson J, Trim R, Danko GP (2008) Externalizing disorders in the offspring from the San Diego prospective study of alcoholism. J Psychiatr Res 42(8):644-652

87. Straussner S, Fewell C (2015) Children of parents who abuse alcohol and other drugs. In: Reupert A, Maybery D, Nicholson J, Gopfert M, Seeman MV (eds) Parental Psychiatric Disorder. Cambridge University Press, Cambridge, pp 138-153

88. Straussner S, Fewell C (2018) A review of recent literature on the impact of parental substance use disorders on children and the provision of effective services. Curr Opin Psychiatry 31(4):363-367

89. Cornelius MD, Goldschmidt L, De Genna NM, Richardson GA, Leech SL, Day R (2010) Improvement in intelligence test scores from 6 to 10 years in children of teenage mothers. J Dev Behav Pediatr 31(5):405-413

90. Makharia A, Nagarajan A, Mishra A, Peddisetty S, Chahal D, Singh Y (2016) Effect of environmental factors on intelligence quotient of children. Ind Psychiatry J 25(2):189-194

91. Turkheimer E, Haley A, Waldron M, D'Onofrio B, Gottesman II (2003) Socioeconomic Status Modifies Heritability of IQ in Young Children. Psychol Sci 14(6):623-628

92. Bountress K, Chassin L (2015) Risk for behavior problems in children of parents with substance use disorders. Am J Orthopsychiatry 85(3):275-286

93. Knopik VS, Heath AC, Bucholz KK, Madden PAF, Waldron M (2009) Genetic and environmental influences on externalizing 
behavior and alcohol problems in adolescence: a female twin study. Pharmacol Biochem Behav. 93(3):313-321

94. Pilowsky DJ, Keyes KM, Hasin DS (2009) Adverse childhood events and lifetime alcohol dependence. Am J Public Health 99(2):258-263

95. Makhija N, Sher L (2007) Childhood abuse, adult alcohol use disorders and suicidal behaviour. QJM An Int J Med 100(5):305-309

96. Straussner S, Fewell C (2011) Children of substance-abusing parents: dynamics and treatment. Springer, New York, NY, p 288

97. Reuben A, Moffitt TE, Caspi A, Belsky DW, Harrington H, Schroeder F et al (2016) Lest we forget: comparing retrospective and prospective assessments of adverse childhood experiences in the prediction of adult health. J Child Psychol Psychiatry 57(10):1103-1112

Publisher's Note Springer Nature remains neutral with regard to jurisdictional claims in published maps and institutional affiliations. 